\title{
Self-esteem, social adjustment and suicidality in affective disorders
}

\author{
E.G. Daskalopoulou ${ }^{1,2}$, D.G. Dikeos ${ }^{1,2}$, G.N. Papadimitriou $^{1,2 \star}$, D. Souery ${ }^{3}$, S. Blairy ${ }^{3}$, \\ I. Massat ${ }^{3}$, J. Mendlewicz ${ }^{3}$, C.N. Stefanis ${ }^{1}$ \\ ${ }^{1}$ University Mental Health Research Institute, Athens University Medical School, Eginition Hospital, 72-74, Vas \\ Sofias Avenue, 11528 Athens, Greece; ${ }^{2}$ Department of Psychiatry, Athens University Medical School, Eginition \\ Hospital, 11528 Athens, Greece; ${ }^{3}$ Department of Psychiatry, Free University of Brussels, Erasme Hospital, 1070 \\ Brussels, Belgium
}

(Received 10 October 2001; accepted 22 May 2002)

\begin{abstract}
Summary - Self-esteem (SE) and social adjustment (SA) are often impaired during the course of affective disorders; this impairment is associated with suicidal behaviour. The aim of the present study was to investigate SE and SA in unipolar or bipolar patients in relation to demographic and clinical characteristics, especially the presence of suicidality (ideation and/or attempt). Forty-four patients, 28 bipolar and 16 unipolar, in remission for at least 3 months, and 50 healthy individuals were examined through a structured clinical interview. SE and SA were assessed by the Rosenberg self-esteem scale and the social adjustment scale, respectively. The results have shown that bipolar patients did not differ from controls in terms of SE, while unipolar patients had lower SE than bipolars and controls. No significant differences in the mean SA scores were found between the three groups. Suicidality during depression was associated only in bipolar patients with lower SE at remission; similar but not as pronounced was the association of suicidality with SA. It is concluded that low SE lasting into remission seems to be related to the expression of suicidality during depressive episodes of bipolar patients, while no similar pattern is evident in unipolar patients. (c) 2002 Éditions scientifiques et médicales Elsevier SAS
\end{abstract}

\section{Self-esteem / Social adjustment / Suicidality / Affective disorder}

\section{INTRODUCTION}

Affective disorder is considered a major public health problem due to its high prevalence, recurrences, treatment resistance, frequent development of chronicity, incapacitation and high risk of suicidal behaviour [1]. The identification of risk factors that may influence the development of the disorder and its course, as well as the construction of a profile of the patient at high risk for recurrences or suicidality is among the major aims of current research in psychiatry. It has been demon- strated through family, twin and adoption studies that genetic factors play an important role in the etiopathogenesis of affective disorder. Thus, the susceptibility to the disease may be due, at least partly, to the genetic component [2-5]. On the other hand, the role of various environmental and psychosocial factors in the development and expression of the disorder should not be underestimated. Among these factors, self-esteem and social adjustment have been reported to influence the onset and course of affective disorder [6-8].

${ }^{*}$ Corresponding author.

E-mail address: ddikeos@cc.uoa.gr (D.G. Dikeos). 
Low self-esteem has been since long associated with depression [9] and has been hypothesized that it may predict, or even contribute to the onset and course of the disease [6,9-14], although the results are not always consistent [15]. Self-esteem during the periods of remission was found in previous studies to be lower in unipolar (UP) and/or bipolar (BP) patients compared to controls $[8,16,17]$.

Regarding social adjustment, it is suggested that impairment in social function may increase the liability for the development of major depression [18], and the mechanism for this transduction has been hypothesized [19]. Patients with affective disorders demonstrate impairment in all the areas of social functioning even when at remission for 2 years [20], but the particular areas of social adjustment do not seem to be equally impaired in UP and BP patients. UP patients are consistently found to be dysfunctional in the areas of social interactions and spare time activities $[7,16,17]$. On the contrary, for BP patients, the results are not consistent, since in one study, impairment was found in the area of contacts with friends [7], in another, in the areas of spare time, family relations and finance [16], and in the third, no impairment was found compared to controls [17].

Suicidality has been found to be associated with low self-esteem [21-27], but this finding has been recently challenged [28-30]. Suicidal behaviour has been also related to impaired social adjustment $[23,31]$ and low global functioning in depressed patients [26]. However, to our knowledge, the association of suicidality with self-esteem and social adjustment has not been examined in remitted patients with affective disorder distinguishing between the groups of UP and BP depressed patients.

The aim of the present study was: (a) to examine self-esteem and social adjustment of patients with affective disorder compared to healthy individuals; (b) to investigate any possible correlation of self-esteem and social adjustment with various demographic and clinical characteristics; and (c) to assess the possible association of suicidality with self-esteem and social adjustment in UP and BP patients in remission.

\section{MATERIALS AND METHODS}

\section{Subjects}

Our sample consisted of 44 patients with affective disorder and 50 healthy individuals. Among the patients, 28 suffered from BP disorder (17 males and 11 females) and the remaining 16 from UP recurrent depression (2 males and 14 females). Patients were selected from a larger sample recruited on a consecutive admission basis from the outpatient services of the Department of Psychiatry of Eginition University Hospital, for a European collaborative project on the genetics of affective disorders [32]. In the present study, only those patients who had a clear diagnosis of UP or BPI disorder and were in total clinical remission for at least three consecutive months were included. The healthy individuals were blood donors consecutively recruited from a blood transfusion service of an Athens general hospital and were mostly relatives and friends of surgical patients. Informed consent was obtained from all the individuals [32].

\section{Diagnosis}

Patients and controls were personally interviewed with the Schedules for Clinical Assessment in Neuropsychiatry (SCAN), a semi-structured psychiatric questionnaire [33]. Concerning the patients, information required to reach diagnosis was also obtained from all the clinical and hospital records available. Final diagnosis was made according to the DSM-IV [34] and ICD-10 [35] criteria. Current remission was considered as total, if no or few significant symptoms persisted, as defined in the "Quality of remissions between episodes" item of the SCAN. The controls were also interviewed with the SCAN for the presence of main symptoms of major psychiatric diagnoses or alcohol/ substance abuse or dependence at the time of examination or at any time during lifetime. All the healthy individuals included in the study were free of any history of psychiatric symptoms, present or past, and were not on any medication. The instruments used to assess self-esteem and social adjustment of all the subjects were the Rosenberg self-esteem scale (SES) [36] and the observer-rated version of the social adjustment scale (SAS) [37]. The SES consists of 10 items, five of which are phrased as a positive statement and five as a negative one, referring to the self. The scale yields a total score of $0-6$, where 0 represents high and 6 represents low self-esteem. The SAS consists of 54 items that are subdivided into four areas of social functioning: work activities including work for pay, housewife/househusband, or student (work), spare time and leisure activities (spare), personal relationships with 
partner, children and extended family (family), and financial condition (finance).

Demographic and clinical characteristics relating to the course of the disease, i.e. age, age at onset, illness duration, duration of current remission, and total number of depressive and/or manic episodes during years of illness were recorded. As an indication of episode severity, the number of depressive or manic symptoms during the worst episode was calculated according to the presence or not of each of the eight symptoms (appetite loss, sleep disturbance, low energy, low interest, guilt/ self-reproach, concentration, suicidal, agitation/ retardation) during the depressive episode, and seven symptoms (active, talkative, thought race, grandiosity, less sleep, distractible, judgement) during the manic episode. In addition, the presence of suicidality, i.e. ideation (defined in the SCAN as intrusive thoughts of suicide or self-injury) or suicidal attempt, during any depressive episode was assessed.

\section{Statistical analysis}

Statistical analysis was performed by analysis of variance (ANOVA) for comparisons of means of SES and SAS scores between the groups of BP, UP patients and controls and by $t$-tests to determine which groups are different, when the ANOVA revealed a statistically significant difference. $t$-Tests were also performed for comparisons between the two groups of patients distinguished according to whether they had expressed suicidality or not. Pearson's correlations were used to test for possible associations between clinical variables and the total score of SES and the total and area scores of SAS. Multiple linear regression analysis was performed to verify the findings and examine possible effects of gender differences.

\section{RESULTS}

The ANOVA showed that the mean total scores of self-esteem were different between the three groups examined (table 1 ). This difference was due to selfesteem being lower for UP patients when compared to controls as well as to BP patients $(t$-tests, $P<0.05$ in both cases), while it did not differ significantly between BP patients and controls (table I). In a multiple linear regression analysis of SES (as dependent variable) from gender and diagnostic status (as predictors), diagnosis of UP disorder remained a predictor of SES total score for the comparison between UP patients and controls (beta $\pm S E=1.01 \pm 0.39, t=2.57, P=0.013$ ), showing that lower self-esteem in UP patients is not due to difference in gender percentages among groups. Comparison of total and area SAS scores, revealed that the overall social adjustment as well as the specific areas as reflected in the SAS subscales, did not differ significantly among the groups of BP, UP patients and normal subjects (table I).

The total SES score and the SAS score (total and areas) correlations with demographic and clinical characteristics are presented in tables II and III. In BP patients, the number of depressive symptoms of the worst depressive episode was negatively correlated to self-esteem, the total number of manic episodes was positively correlated to self-esteem and the quality of family relations was negatively correlated to the age at onset of the disease (table II). In a stepwise multiple regression of SES as dependent variable and all the

Table I. Scores (mean \pm S.D.) in the SES ${ }^{\mathrm{a}}$ and in the $\mathrm{SAS}^{\mathrm{a}}$ (total score and area subscores) in patients with BP, UP affective disorder and controls.

\begin{tabular}{|c|c|c|c|c|c|}
\hline & \multirow[t]{2}{*}{$\mathrm{BP}(n=28)$} & \multirow[t]{2}{*}{$\mathrm{UP}(n=16)$} & \multirow[t]{2}{*}{ Controls $(n=50)$} & \multicolumn{2}{|c|}{ ANOVA } \\
\hline & & & & $\mathrm{F}$ & $\mathrm{P}$ \\
\hline SES & $1.36 \pm 1.22$ & $2.57 \pm 1.91$ & $1.26 \pm 1.01$ & 6.316 & $0.003^{\mathrm{b}}$ \\
\hline SAS total score & $1.67 \pm 0.40$ & $1.59 \pm 0.27$ & $1.70 \pm 0.31$ & 0.899 & 0.411 \\
\hline \multicolumn{6}{|l|}{ SAS area subscores } \\
\hline Work & $1.26 \pm 0.29$ & $1.35 \pm 0.32$ & $1.43 \pm 0.29$ & 2.272 & 0.110 \\
\hline Spare & $1.76 \pm 0.42$ & $1.68 \pm 0.48$ & $1.75 \pm 0.49$ & 0.205 & 0.815 \\
\hline Family & $1.29 \pm 0.51$ & $1.45 \pm 0.31$ & $1.53 \pm 0.45$ & 2.415 & 0.095 \\
\hline Finance & $1.61 \pm 1.10$ & $1.50 \pm 0.97$ & $1.70 \pm 1.01$ & 0.245 & 0.783 \\
\hline
\end{tabular}

${ }^{a}$ The lower are the self-esteem and the social adjustment, the higher are the SES and SAS scores.

${ }^{\mathrm{b}} t$-Tests for determining which groups differ regarding SES score, for which the ANOVA shows significant difference: BP vs. controls: $t=0.38$, $\mathrm{df}=76$, not significant; UP vs. controls: $t=3.47, \mathrm{df}=62, P=0.026$; BP vs. UP: $t=-2.50, \mathrm{df}=40, P=0.016$. 
Table II. SES $S^{a}$ total score and SAS ${ }^{a}$ total and subscales scores in BP patients: relation to clinical characteristics ${ }^{b}$.

\begin{tabular}{|c|c|c|c|c|c|c|}
\hline & SES Total & & & SAS & & \\
\hline & & Total & Work & Spare & Family & Finance \\
\hline Age & -0.12 & -0.11 & 0.06 & -0.18 & 0.30 & 0.05 \\
\hline Age at onset & -0.03 & 0.15 & 0.26 & -0.02 & $0.48^{*}$ & -0.06 \\
\hline Illness duration & -0.15 & -0.31 & -0.11 & -0.26 & -0.01 & 0.13 \\
\hline Duration of current remission & -0.26 & -0.15 & -0.01 & 0.06 & -0.25 & 0.25 \\
\hline Number of depressive episodes & -0.01 & 0.11 & -0.17 & -0.23 & 0.34 & -0.18 \\
\hline Number of manic episodes & $-0.42^{*}$ & -0.11 & -0.12 & -0.05 & 0.01 & -0.15 \\
\hline Number of depressive symptoms & $0.49^{* *}$ & 0.20 & 0.10 & 0.01 & 0.29 & -0.04 \\
\hline Number of manic symptoms & -0.16 & 0.03 & 0.38 & 0.20 & -0.15 & 0.29 \\
\hline
\end{tabular}

${ }^{\text {a }}$ The lower the self-esteem and the social adjustment, the higher the SES and SAS scores.

bThe numbers represent Pearson's correlation coefficients $(r)$.

*Correlation is significant at the 0.05 level (2-tailed).

**Correlation is significant at the 0.01 level (2-tailed).

clinical characteristics examined (current age, age at onset, number of episodes and symptoms of depressive and manic episodes, duration of illness and duration of remission) as predictors, the negative correlation of self-esteem and number of symptoms during the worst depressive episode was confirmed; this variable was the only one to enter the model (beta $\pm S E=0.32 \pm 0.12$, $t=2.79, P=0.013)$. In UP patients, the age at onset of the disease was negatively correlated to self-esteem and current patient age was positively correlated to perceived financial difficulties (table III). The first of these findings was further supported by stepwise multiple regression with self-esteem score as dependent and the clinical characteristics as predictors, where age at onset was the only variable to enter the model (beta $\pm \mathrm{SE}=0.11 \pm 0.04, t=2.92, P=0.015$ ).

Regarding suicidality during depressive episodes, relevant data existed for $24 \mathrm{BP}$ and $14 \mathrm{UP}$ patients. Among them, serious suicidal ideation and/or at least one suicide attempt were reported in nine BP and five
UP patients. When BP patients were divided into two groups according to the presence or absence of suicidality, the mean SES scores of these groups were $2.22 \pm 1.56$ and $0.93 \pm 0.80$, respectively $(P=0.013)$. No significant difference between similar groups of UP patients $(3.00 \pm 1.22$ vs. $2.33 \pm 2.24)$ was found (Table $I V)$. The mean total SAS scores between suicidal and non-suicidal groups of patients, also differed in BP but not in UP patients. The difference in SAS scores between the two groups of BP patients, however, was not pronounced and did not reach statistical significance $(P=0.085$, Table $I V)$.

\section{DISCUSSION}

The results of the present study show that remitted BP patients do not differ from controls in terms of selfesteem scores. On the contrary, remitted UP patients have lower self-esteem than controls, as well as that of BP patients. Older age at onset for UP patients and the

Table III. SES ${ }^{a}$ total score and $S A S^{a}$ total and subscales scores in UP patients: relation to clinical characteristics ${ }^{b}$.

\begin{tabular}{lcrrrrr}
\hline & SES Total & \multicolumn{3}{c}{ SAS } \\
\cline { 3 - 7 } & & Total & Work & Spare & Family & Finance \\
\hline Age & 0.26 & -0.06 & -0.07 & 0.09 & -0.21 & $-0.51^{*}$ \\
Age at onset & $0.60^{*}$ & 0.05 & 0.50 & 0.42 & -0.28 & -0.29 \\
Illness duration & -0.40 & -0.08 & -0.10 & -0.33 & 0.12 & -0.09 \\
Duration of current remission & -0.11 & -0.18 & 0.16 & 0.11 & -0.24 & -0.13 \\
Number of depressive episodes & -0.31 & -0.24 & -0.09 & -0.31 & 0.01 & -0.15 \\
Number of depressive symptoms & 0.41 & 0.11 & -0.20 & 0.26 & -0.27 & 0.08 \\
\hline
\end{tabular}

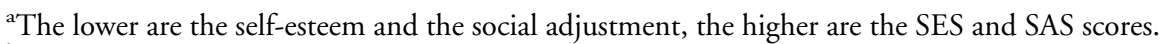

bThe numbers represent Pearson's correlation coefficients $(r)$.

${ }^{*}$ Correlation is significant at the 0.05 level (2-tailed). 
Table IV. Total scores (mean \pm S.D.) in the $S S^{a}$ and in the $S A S^{a}$ in patients with BP and UP affective disorder according to the presence or not of suicidality (serious suicidal thoughts and/or at least one suicide attempt during any depressive episode).

\begin{tabular}{|c|c|c|c|c|}
\hline & \multicolumn{2}{|c|}{ Suicidality } & \multirow[t]{2}{*}{$t$-Tests } \\
\hline & & Present & Absent & \\
\hline \multirow[t]{2}{*}{$\mathrm{BP}$} & SES & $2.22 \pm 1.56$ & $0.93 \pm 0.80$ & $\begin{array}{l}t=-2.69, \mathrm{df}=22, \\
P=0.013\end{array}$ \\
\hline & SAS & $1.84 \pm 0.39$ & $1.56 \pm 0.36$ & $\begin{array}{l}t=-1.80, \mathrm{df}=22, \\
P=0.085\end{array}$ \\
\hline \multirow[t]{2}{*}{ UP } & SES & $3.00 \pm 1.22$ & $2.33 \pm 2.24$ & $\begin{array}{l}t=-0.61, \mathrm{df}=12, \\
\text { N.S. }\end{array}$ \\
\hline & SAS & $1.54 \pm 0.18$ & $1.62 \pm 0.32$ & $\begin{array}{l}t=0.53, \mathrm{df}=12, \\
\text { N.S. }\end{array}$ \\
\hline
\end{tabular}

${ }^{a}$ The lower the self-esteem and the social adjustment, the higher the SES and SAS total scores.

${ }^{\mathrm{b}}$ N.S.: not significant.

severity of depressive episodes for BP patients negatively affect self-esteem. Regarding social adjustment, no significant differences in the mean social adjustment scores between BP patients, UP patients and controls were detected. Moreover, no association of the social adjustment total score and area subscores with clinical characteristics was found, as the only two correlations observed (a positive between financial status and patients' current age for UP patients and a negative between age of onset of the disease and family relations for BP patients) had a weak statistical significance that could not stand the Bonferroni corrections. Further, suicidality (suicidal ideation and/or attempt) during depression was associated with lower self-esteem at remission; similar but not as pronounced was the association of suicidality with social adjustment. These findings were noted only for the BP and not for the UP patients.

The findings relevant to self-esteem are in line with previous studies in which the self-esteem of UP patients during remission was consistently found to be lower in comparison to that of controls $[8,16,17]$. For BP disorder, patients' self-esteem was not different than that of controls in one study [8], but was lower in two other studies $[16,17]$. Population differences among studies may explain the discrepancies regarding self-esteem in BP patients, since it has been supported that the concept of self-esteem is under strong cultural influence [38]. Indeed, the studies with the positive findings were conducted on Italian and Jewish populations [16,17], while the negative results referred to Belgian [8] and Greek subjects in the present study. Self-esteem in UP patients, in contrast, seems to be independent of the origin of the sample. Low self-esteem has been since long associated with depression [9] and has been found to exist before the onset of and after the recovery from a depressive episode $[6,11,39]$. Moreover, it has been hypothesized that low self-esteem may predict, or even contribute to the onset of depression $[6,9,11]$ as well as influence its course $[12,13]$. In the present study, low self-esteem was associated with the severity of depressive episodes in BP patients and with later age at onset in UP patients; these findings were supported by multiple regression analysis. The results of other studies regarding the relationship of self-esteem and the course and severity of affective disorders are controversial; low self-esteem was found to be associated with development of chronicity [13] and with non-full remission in UP patients [14], but it was also found not to be correlated with the recurrence of BP nor UP affective disorder [15]. It is possible that the difficulty in clearly defining self-esteem and the relatively narrow target of the scales measuring it [38] as well as the possibility of self-esteem reflecting to some extent residual depressive symptoms are major factors influencing the discrepant outcomes of the various studies.

The results of the present study concerning social adjustment are at variance with previous findings showing various levels of impairment of social adjustment in affective disorder patients [7,17,20,40-43]. In those studies, however, the areas of impairment were not the same between BP and UP patients, the impairment was not always apparent in BP patients, and was dependent on the severity of the disease $[17,40]$. Additionally, the areas of social adjustment that were reported to be impaired in BP patients were culturally influenced, since they seemed to vary between studies conducted on different populations $[7,16]$. Furthermore, the relationship of social adjustment scores with clinical characteristics of severity and course of affective disorders was found in some studies [14,15,44-46], but not in others $[7,47]$. It has also been suggested that, especially in BP patients, the magnitude of the problem with impaired social adjustment might be concealed by the utilization of self-report scales, since patients have a more superficial investment in social relations [48].

Finally, the finding regarding the association of suicidality with lower self-esteem and social adjustment is in accordance with other studies in which suicidality has been consistently found to be associated with low self-esteem [21-27]; it must be noted, however, that low self-esteem was not always found to be an indepen- 
dent variable associated to suicidality, but was dependent on the levels of depression or personality and cognitive styles $[28,29]$. The majority of these studies [21-29] was conducted on adolescent populations. Three out of four studies that included adult subjects, used general population samples [22,23,27]. In the only study that was conducted on adult patients suffering from affective disorder, subjects with major depression, dysthymia and adjustment disorder with depressed mood were included and suicidality was defined (as in our study) as the presence of suicidal ideation and/or attempt [26]. In that study, suicidality was found to be associated with low self-esteem in depressed patients, but the assessment of self-esteem was performed during the episode of depression. In our study, the assessment of self-esteem was done at remission of at least 3 months, and no association between low self-esteem and suicidality was observed for UP patients. On the contrary, in BP patients suicidality was found to be associated with low self-esteem at remission. No other study has focused on a similar distinction of the relationship of suicidality and self-esteem according to characterization of depressed patients as UP or BP. Our results indicate that low self-esteem that lasts into remission is a contributing risk factor for the appearance of suicidal ideation during the depressive episodes of BP patients; a similar pattern could not be proven for UP patients. Suicidality has been found to be related to low satisfaction with social support in adolescents of the general population [23], to social withdrawal in schizophrenic and affective disorder patients [31] and to low global functioning the year before hospitalization in adult in-patients with depression, dysthymia and adjustment disorder with depressed mood [26]. In the two latter studies that included clinical samples, however, no separate analysis has been performed for affective disorder patients according to the type of their diagnosis. Our results suggest that, as with self-esteem, social adjustment in remission is lower only in BP and not in UP patients, but the small number of our sample and the high probability of a type I error do not allow for firm conclusions to be drawn.

A limitation of the present study is that it cannot be totally ruled out that self-esteem, as was measured, reflects remaining depressive symptomatology. Although no specific assessment of possible current depressive symptoms was made (e.g. through a depression scale), the fact that all the patients were in total clinical remission (with no significant symptoms of depression) for at least 3 months supports that the presence of depressive symptomatology may not have interfered substantially with the results. Another limitation is that the control group was not gender and age matched to the patients. However, the multiple linear regression confirmed that gender differences did not influence the results. Differences in age distribution remain a drawback and their effect could not be totally assessed, as the control group (being blood-donors) was substantially younger than UP, although not younger than BP patients.

In summary, unipolar patients had lower self-esteem than bipolar patients and controls, while bipolar patients did not differ from controls in terms of selfesteem. No differences among the three groups were found regarding social adjustment. Low self-esteem and, possibly, social adjustment between the episodes of the disorder seem to be associated with the presence of suicidal thoughts and/or attempts in bipolar but not in unipolar patients. This finding needs to be further explored in future studies and should be taken into consideration in the long-term management of affective disorder.

\section{REFERENCES}

1 Judd LL. Mood disorders in the general population represent an important and worldwide public health problem. Int Clin Psychopharmacol 1995;10(Suppl 4):5-10.

2 Mendlewicz J. Population and family studies in depression and mania. Br J Psychiatry 1988;3:16-25.

3 Tsuang MT, Faraone SV. The genetics of mood disorders. Baltimore: Johns Hopkins University Press; 1990.

4 Stefanis CN, Dikeos DG, Papadimitriou GN. Clinical strategies in genetic research. In: Mendlewicz J, Papadimitriou GN, editors. Genetics of mental disorders Part I: theoretical aspects. Bailliere's Clinical Psychiatry, International Practice and Research. London: Bailliere Tindall; 1995. p. 1-18.

5 Souery D, Papadimitriou GN, Mendlewicz J. New molecular genetic studies in affective disorders. In: Papadimitriou GN, Mendlewicz J, editors. Genetics of mental disorders Part II: clinical issues. Bailliere's Clinical Psychiatry, International Practice and Research. London: Bailliere Tindall; 1996. p. 1-13.

6 Brown G, Andrews B, Bifulco A, Veiel H. Self-esteem and depression. 1. Measurement issues and prediction of onset. Soc Psychiatry Psychiatr Epidemiol 1990;25:200-9.

7 Bauwens F, Tracy A, Pardoen D, Van der Elst M, Mendlewicz J. Social adjustment of remitted bipolar and unipolar out-patients. A comparison with age- and sex-matched controls. Br J Psychiatry 1991;159:239-44.

8 Pardoen D, Bauwens F, Tracy A, Martin F, Mendlewicz J. Selfesteem in recovered bipolar and unipolar out-patients. $\mathrm{Br} \mathrm{J}$ Psychiatry 1993;163:755-62.

9 Beck AT. Depression: clinical, experimental and theoretical aspects. New York: Harper \& Row; 1967.

10 Winters KC, Neale JM. Mania and low self esteem. J Abnormal Psychol 1985;94:282-90.

11 Miller PM, Kreitman NB, Ingham JG, Sashidharan SP. Self- 
esteem, life stress and psychiatric disorder. J Affect Disord 1989; 17:65-75.

12 Brown G, Bifulco A, Veiel H, Andrews B. Self-esteem and depression. 2. Social correlates of self-esteem. Soc Psychiatry Psychiatr Epidemiol 1990;25:225-34.

13 Bothwell R, Scott J. The influence of cognitive variables on recovery in depressed inpatients. J Affect Disord 1997;43: 207-12.

14 Ezquiaga E, Garcia A, Pallares T, Bravo MF. Psychosocial predictors of outcome in major depression: a prospective 12-month study. J Affect Disord 1999;52:209-16.

15 Staner L, Tracy A, Dramaix M, Genevrois C, Vanderelst M, Vilane A, et al. Clinical and psychosocial predictors of recurrence in recovered bipolar and unipolar depressives: a one-year controlled prospective study. Psychiatry Res 1997;69:39-51.

16 Serretti A, Cavallini MC, Macciardi F, Namia C, Franchini L, Lipp O, et al. Social adjustment and self-esteem in remitted patients with mood disorders. Eur Psychiatry 1999;14:137-42.

17 Shapira B, Zislin J, Gelfin Y, Osher Y, Gorfine M, Souery D, et al. Social adjustment and self-esteem in remitted patients with unipolar and bipolar affective disorder: a casecontrol study. Compr Psychiatry 1999;40:24-30.

18 Dohrenwend BP, Levav I, Shrout PE, Schwartz S, Naveh G, Link BG, et al. Socioeconomic status and psychiatric disorders: the causation-selection issue. Science 1992;255:946-52.

19 Post RM. Transduction of psychosocial stress into the neurobiology of recurrent affective disorder. Am J Psychiatry 1992;149: 999-1010.

20 Coryell W, Scheftner W, Keller M, Endicott J, Maser J, Klerman GL. The enduring psychosocial consequences of mania and depression. Am J Psychiatry 1993;150:720-7.

21 Kienhorst CW, De Wilde EJ, Van Den Bout J, Diekstra RF, Wolters WH. Characteristics of suicide attempters in a population-based sample of Dutch adolescents. Br J Psychiatry 1990; 156:243-8.

22 Angst J, Degonda M, Ernst C. The Zurich Study: XV. Suicide attempts in a cohort from age 20 to 30 . Eur Arch Psychiatry Clin Neurosci 1992;242:135-41.

23 De Man AF, Leduc CP, Labreche-Gauthier L. Correlates of suicide ideation in French-Canadian adults and adolescents: a comparison. J Clin Psychol 1992;48:811-6.

24 Overholser JC, Adams DM, Lehnert KL, Brinkman DC. Selfesteem deficits and suicidal tendencies among adolescents. J Am Acad Child Adolesc Psychiatry 1995;34:919-28.

25 Plutchnik R, Botsis AJ, Van Praag HM. Psychopathology, self-esteem, sexual and ego functions as correlates of suicide and violence risk. Arch Suicide Res 1995;1:1-12.

26 Van Gastel A, Schotte C, Maes M. The prediction of suicidal intent in depressed patients. Acta Psychiatr Scand 1997;96: 254-9.

27 Vilhjamsson R, Kristjansdottir G, Sveinbjarnardottir E. Factors associated with suicide ideation in adults. Soc Psychiatry Psychiatr Epidemiol 1998;33:97-103.

28 Beautrais AL, Jouce PR, Mulder RT. Personality traits and cognitive styles as risk factors for serious suicide attempts among young people. Suicide Life Threat Behav 1999;29:37-47.

29 Hawton K, Kingsbury S, Steinhardt K, James A, Fagg J. Repetition of deliberate self-harm by adolescents: the role of psychological factors. J Adolesc 1999;22:369-78.

30 Nasser EH, Overholser JC. Assessing varying degrees of lethality in depressed adolescent suicide attempters. Acta Psychiatr Scand 1999;99:423-31.
31 Ahrens B, Linden M. Is there a suicidality syndrome independent of specific major psychiatric disorder? Results of a split half multiple regression analysis. Acta Psychiatr Scand 1996;94: 79-86.

32 Souery D, Lipp O, Serretti A, Mahieu B, Rivelli SK, Cavallini C, et al. European Collaborative Project on Affective Disorders: interactions between genetic and psychosocial vulnerability factors. Psychiatr Genet 1998;8:197-205.

33 World Health Organization. Schedules for Clinical Assessment in Neuropsychiatry (SCAN). Geneva: World Health Organization; 1992.

34 American Psychiatric Association. Diagnostic and Statistical Manual of Mental Disorders, 4th ed. Washington, DC: American Psychiatric Association; 1994.

35 World Health Organization. The ICD-10 classification of mental and behavioural disorders: clinical descriptions and diagnostic guidelines, 1992.

36 Rosenberg M. The measurement of self-esteem. In: Rosenberg $M$, editor. Society and the adolescent self-image. New Jersey: Princeton University Press; 1965. p. 16-35.

37 Weissman MM, Bothwell S. Assessment of social adjustment by patient self-report. Arch Gen Psychiatry 1976;33:1111-5.

38 Robson PJ. Self-esteem. A psychiatric view. Br J Psychiatry 1988;153:6-15.

39 Ingham JG, Kreitman NB, Miller PM, Sashidharan SP, Surtees PG. Self-appraisal, anxiety and depression in women. A prospective enquiry. Br J Psychiatry 1987;151:643-51.

40 Perugi G, Maremmani I, McNair DM, Cassano GB, Akiskal HS. Differential changes in areas of social adjustment from depressive episodes through recovery. J Affect Disord 1988;15:39-43.

41 Hays RD, Wells KB, Sherbourne CD, Rogers W, Spritzer K. Functioning and well-being outcomes of patients with depression compared with chronic general medical illnesses. Arch Gen Psychiatry 1995;52:11-9.

42 Cannon M, Jones P, Gilvarry C, Rifkin L, McKenzie K, Foerster A, Murray RM. Premorbid social functioning in schizophrenia and bipolar disorder: similarities and differences. Am J Psychiatry 1997;154:1544-50.

43 Blairy S, Souery D, Papadimitriou GN, Dikeos DG, Lerer B, Kaneva R, et al. Association between unemployment and social adjustment and self-esteem in bipolar patients compared to normal subjects. World Federation of Societies of Biological Psychiatry, European Regional Congress, Florence, Italy. Abstract Book; 1999 n. 74.

44 Gitlin MJ, Swendsen J, Heller TL, Hammen C. Relapse and impairment in bipolar disorder. Am J Psychiatry 1995;152: 1635-40.

45 Bauwens F, Pardoen D, Staner L, Dramaix M, Mendlewicz J. Social adjustment and the course of affective illness: a one-year controlled longitudinal study involving bipolar and unipolar out-patients. Depress Anxiety 1998;8:50-7.

46 Moos RH, Croncite RC. Symptom-based predictors of a 10-year chronic course of treated depression. J Nerv Ment Dis 1999; 187:360-8.

47 Nierenberg AA, Grossbard SJ, Fava M, Rosenbaum JF. Social adjustment does not predict depressive relapse during continuation fluoxetine therapy. J Affect Disord 1995;34:73-7.

48 Matussek P, Wolfgang PD. Personality attributes of depressive patients. Arch Gen Psychiatry 1983;40:783-90. 